\title{
Pulmonary Barotrauma Including Huge Pulmonary Interstitial Emphysema in an Adult with Status Asthmaticus: Diagnostic and Therapeutic Challenges
}

\author{
Ahmed Khedher, Khaoula Meddeb, Nesrine Sma, Abdelbaki Azouzi, Nesrine Fraj, Mohamed Boussarsar \\ Medical Intensive Care Unit, Farhat Hached Hospital, Sousse, Tunisia
}

\begin{abstract}
Received: $15 / 12 / 2017$
Accepted: 03/01/2018

Published: 02/03/2018
\end{abstract}

\begin{abstract}
How to cite this article: Khedher A, Meddeb K, Sma N, Azouz A, Fraj N, Boussarsas M. Pulmonary barotrauma including huge pulmonary interstitial emphysema in adult with status asthmaticus: diagnostic and therapeutic challenges. EJCRIM 2018;5: doi:10.12890/2018_000823.
\end{abstract}

Conflicts of Interests: The Authors declare that there are no competing interests.

This article is licensed under a Commons Attribution Non-Commercial 4.0 License

\section{ABSTRACT}

Introduction: Pulmonary interstitial emphysema is a rare finding defined as abnormal air collection inside the lung interstitial tissues. Described more frequently in ventilated new-borns, pulmonary interstitial emphysema is an uncommon barotrauma-related complication in adults. Management and clinical sequelae are poorly described.

Patient: We describe the case of a 64-year-old man who presented with huge pulmonary interstitial emphysema together with simultaneous pulmonary barotrauma in status asthmaticus requiring invasive ventilation.

Discussion: There are no guidelines for the management of such complications and their possible sequelae but conservative treatment seems to be effective. The treatment of our patient is described.

\section{LEARNING POINTS}

- We describe ventilation-induced tension pulmonary interstitial emphysema combined with contralateral pneumothorax, pneumomediastinum, pneumoperitoneum and subcutaneous emphysema which developed immediately after difficult airway management of acutely decompensated asthma in an adult.

- The present case highlights the importance of crash induction, cautious airway management and protective re-ventilation in the management of acute respiratory failure with dynamic hyperinflation, such as status asthmaticus.

- Minimally invasive management by percutaneous trans-thoracic intrabullous chest-tube drainage is feasible, safe and relatively effective.

\section{KEYWORDS}

Pulmonary interstitial emphysema, status asthmaticus, barotrauma, mechanical ventilation

\section{INTRODUCTION}

The use of mechanical ventilation in acute asthma is closely associated with some life-threatening complications such as pneumothorax, pneumomediastinum, pneumoperitoneum and subcutaneous emphysema ${ }^{[1]}$. There are clear guidelines for the management of each of these complications. However, pulmonary interstitial emphysema is an extremely uncommon barotrauma-related condition in adults ${ }^{[2]}$, so physicians have little experience in recognising and managing this complication. 


\section{CASE REPORT}

A 64-year-old man presented with a 1-week history of episodes of progressively worsening shortness of breath with wheezing. He had a history of moderate persistent allergic asthma and a total resection of a mediastinal mass in December 2012. Twenty-four hours before his admission to the ICU, he presented to a primary hospital with status asthmaticus requiring invasive ventilation because of rapid patient fatigue with altered level of consciousness despite optimal therapy. The conditions surrounding intubation were reported to be difficult. The chest radiograph (Fig. 1a) showed left-sided pneumothorax and increased transparency of the right lung field mimicking contralateral pneumothorax. On admission to the ICU, the patient was asynchronized with the ventilator and required deep analgosedation and muscle paralysis agents. He was afebrile, with a heart rate of 130 beats/min and blood pressure of 70/40 mmHg. He presented subcutaneous emphysema localized in the chest, breast and neck. His breath sounds were distant on both sides with wheezes. Volume-controlled ventilation delivered a 1.0 fraction of inspired oxygen $\left(\mathrm{FIO}_{2}\right)$, tidal volume of $6 \mathrm{ml} / \mathrm{kg}$, respiratory rate of 12 and zero external PEEP. The highest peak inspiratory pressure was $70 \mathrm{cmH}_{2} \mathrm{O}$, while intrinsic positive end expiratory pressure (PEEPi) was $14 \mathrm{cmH}_{2} \mathrm{O}$. Arterial blood gas values were: $\mathrm{pH}, 7.2 ; \mathrm{PaCO}_{2}, 66 \mathrm{mmHg}$; and $\mathrm{PaO}_{2}, 180 \mathrm{mmHg}$. The white blood cell count was 15,200/mm; blood urea nitrogen, $14 \mathrm{mmol} / \mathrm{l}$; serum creatinine, $178 \mu \mathrm{mol} / \mathrm{l}$; and lactates, $3.2 \mathrm{mmol} / \mathrm{l}$.

The chest CT scan showed a giant right perivascular and peribronchial emphysema consistent with pulmonary interstitial emphysema, an anterior left-sided pneumothorax, a pneumomediastinum, a non-compressive pneumoperitoneum and subcutaneous emphysema (Fig. 2a). Insertion of a chest tube on the left side allowed total lung re-expansion, improving oxygenation, and ventilatory and haemodynamic parameters. The patient was treated with fluid expansion, intravenous corticosteroids, $\beta 2$-agonists and antibiotics. The pneumomediastinum and subcutaneous emphysema resolved spontaneously and the chest tube was withdrawn on day 12 . During his ICU stay, the patient presented altered lung compliance, probably related to the right-sided huge compressive pulmonary interstitial emphysema. Watchful waiting was the therapeutic option initially adopted, leading to partial regression of the pulmonary interstitial emphysema documented on the chest CT scan on day 15 (Fig. 2b). The residual emphysema bullae were drained to improve an already compromised respiratory status associated with ventilatory weaning difficulties related to ICU-acquired weakness. Chest tube withdrawal after total regression was twice followed by recurrence and the development of sepsis due to a suppurative collection in the same sequelar basal emphysema bullae (Fig. 3).

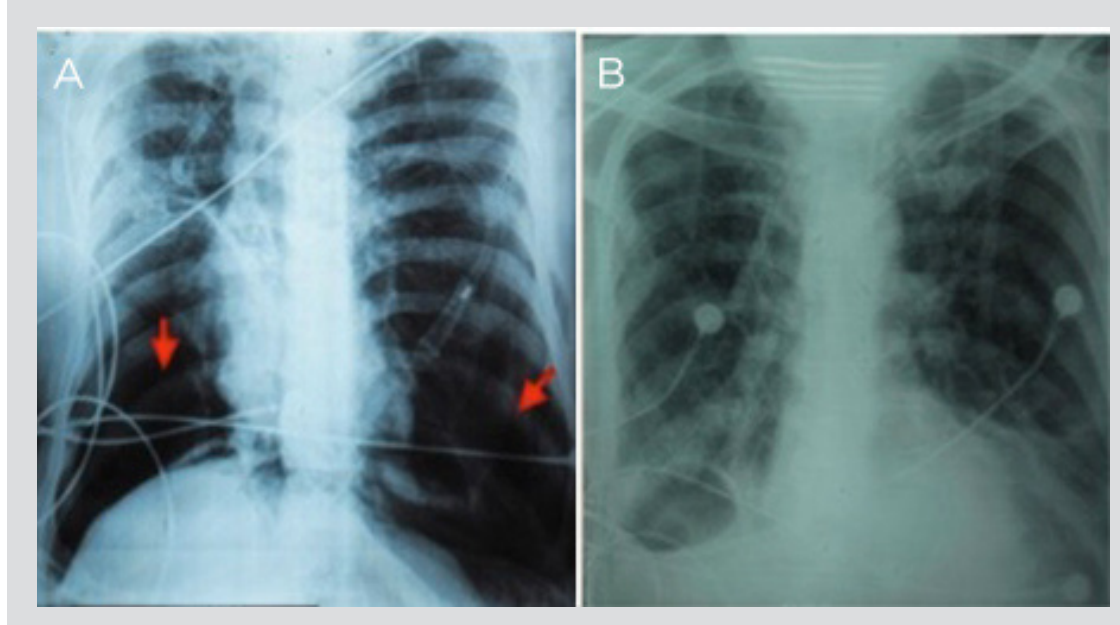

Figure 1. (a) Chest $x$-ray at admission showing a left pneumothorax and basal right lung increased transparency.

(b) Chest $x$-ray at discharge showing a sequelar air-filled interstitial basal right-sided cyst.

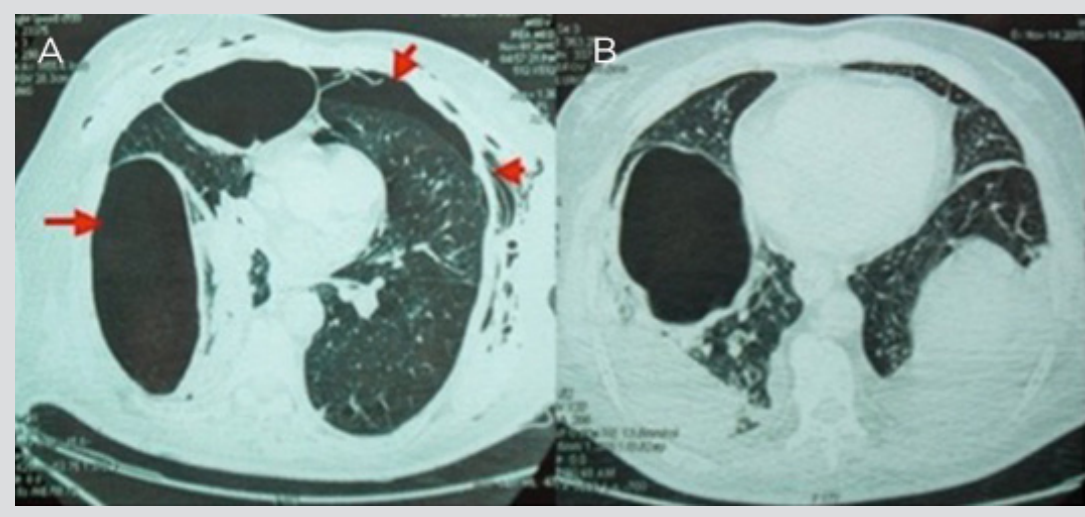

Figure 2. (a) Chest CT scan showing giant right-sided perivascular peribronchial emphysema, anterior left-sided pneumothorax, pneumomediastinum and subcutaneous emphysema. (b) Chest CT scan on day 15 showing residual emphysema bullae. 
On each occasion, CT scan-guided chest drainage and intravenous antibiotics were required. Microbiological cultures were positive for endogenous anaerobic bacteria. The chest tube was finally withdrawn on day 62 leaving behind a localized persistent air-filled interstitial basal right-sided cyst (Fig. 1b). The patient was discharged from the ICU on day 72 under home ventilation.

\section{Methods and Procedures}

We searched PubMed using the keywords 'pulmonary interstitial emphysema', 'barotrauma', 'mechanical ventilation', 'asthma', 'adult' and 'treatment'. Our search revealed no articles. When we withdrew the key word 'asthma', the search identified 11 articles, most of which were case series published from 1979 to 2000 . In most cases, acute respiratory distress syndrome (ARDS) was the most common pulmonary condition underlying pulmonary interstitial emphysema ${ }^{[2-7]}$.

\section{DISCUSSION}

Pulmonary barotrauma is mainly mediated by non-physiological pressure differences between overdistended alveoli and the surrounding tissues and spaces. Although most often occurring in conjunction with ARDS, barotrauma can occur in ventilated patients with underlying diseases characterized by airflow obstruction and dynamic lung hyperinflation ${ }^{[1]}$. The clinical presentation can be asymptomatic or lead to respiratory distress usually following a large tension pneumothorax. Other presentations including pulmonary interstitial emphysema can occur alone or in combination ${ }^{[1]}$. The present patient, admitted for acute severe asthma, simultaneously developed five mechanical ventilationinduced barotrauma conditions: left-sided pneumothorax, contralateral tension pulmonary interstitial emphysema, pneumomediastinum, pneumoperitoneum and subcutaneous emphysema. Caused by the dissipation of air from the alveoli or the terminal bronchioles into the pulmonary interstitium, pulmonary interstitial emphysema is usually an iatrogenic pulmonary condition of the ventilated lungs of a premature newborn ${ }^{[2]}$.

The large size of the emphysema in our case was another notable peculiarity ${ }^{[3,4]}$. The diagnosis of pulmonary interstitial emphysema based only on chest $x$-ray findings is difficult. A CT scan is necessary because it is more sensitive allowing ipsilateral pneumothorax to also be ruled out $^{[3]}$. The self-expanding air leak process is maintained by mechanical ventilation, which may result in significant expansion over only few hours. Once formed, the air cysts create dead space by compressing adjacent normal lung tissue. In the present case, the escaped air created a giant pulmonary interstitial emphysema in a couple of hours. Gas exchange was initially compromised with a $\mathrm{PaO}_{2} / \mathrm{FiO}{ }_{2}$ ratio below 200 for 1 week.

Interstitial air can spontaneously resolve, progress with further air-leak into adjacent space causing, for example, a secondary pneumothorax, or form diffused or localized persistent pulmonary interstitial emphysema in which infection is a reported complication ${ }^{[4]}$. The main treatments for new-borns are: lateral decubitus positioning, selective intubation or artificial pneumothorax ${ }^{[5,6]}$. Lobectomy and pneumonectomy are rarely used ${ }^{[7]}$. The choice between conservative or surgical management of pulmonary interstitial emphysema depends largely on the severity of the condition and the stability of the patient; there are no relevant guidelines. The present case was initially managed by lateral positioning under permissive hypercapnia ventilation leading to spontaneous partial resolution. 
Subsequently, the patient was managed safely by chest drainage. CT scan-guided intracavitary drainage of suppurative collections under local anaesthesia was required twice after the first intra-bullae tube withdrawal.

In conclusion, pulmonary interstitial emphysema is a rare ventilatory support-related life-threatening side effect in an acutely ill adult with asthma. Its simultaneous occurrence with four other barotrauma pulmonary conditions is exceptional.

There are few reports on the management of this condition and its clinical sequelae in critically ill adult patients, and thus management and its timing is difficult. Early CT scan-guided intercostal tube thoracostomy could improve outcome and should be tried as a first-line treatment.

\section{REFERENCES}

1. Marini JJ. Ventilator-associated problems related to obstructive lung disease. Resp Care 2013;58:938-949.

2. Al-Abdi SY, Singhal N. Pulmonary interstitial emphysema and continuous positive airway pressure in a premature infant. Saudi Med J 2005;26:1627-1629.

3. Donnelly LF, Lucaya J, Ozelame V, Frush DP, Strouse PJ, Sumner TE, et al. CT findings and temporal course of persistent pulmonary interstitial emphysema in neonates: a multiinstitutional study. Am J Roentgenol 2003;180:1129-1133.

4. Unger JM, England DM, Bogust GA. Interstitial emphysema in adults: recognition and prognostic implications. J Thorac Imaging 1989;4:86-94.

5. Schwartz AN, Graham CB. Neonatal tension pulmonary interstitial emphysema in bronchopulmonary dysplasia: treatment with lateral decubitus positioning. Radiology 1986;161:351-354.

6. Chalak LF, Kaiser JR, Arrington RW. Resolution of pulmonary interstitial emphysema following selective left main stem intubation in a premature newborn: an old procedure revisited. Paediatr Anaesth 2007;17:183-186.

7. Matta R, Matta J, Hage P, Nassif Y, Mansour N, Diab N. Diffuse persistent interstitial pulmonary emphysema treated by lobectomy. Ann Thorac Surg 2011;92:73-75. 